\title{
Flame spread over twin electrical wires with applied DC electric fields
}

\author{
Sun Ho Park ${ }^{\mathrm{a}}$, Min Seong Kang ${ }^{\mathrm{a}}$, Min Suk Cha ${ }^{\mathrm{b}, *}$, Jeong Park ${ }^{\mathrm{a}, *}$, Suk Ho Chung ${ }^{\mathrm{b}}$ \\ a Department of Mechanical Engineering, Pukyong National University, Busan, Republic of Korea \\ ${ }^{\mathrm{b}}$ Clean Combustion Research Center, King Abdullah University of Science and Technology (KAUST), Thuwal, Saudi Arabia
}

\section{A R T I C L E I N F O}

\section{Article history:}

Received 25 March 2019

Revised 3 September 2019

Accepted 4 September 2019

\section{Keywords:}

Electrical wire

Electric field

Flame spread rate

Electrospray

Di-electrophoresis

\begin{abstract}
A B S T R A C T
The effect of DC electric field on the characteristics of flame spread over polyethylene-insulated twin electrical wires was studied by varying wire gap $(S)$ and voltage $\left(V_{\mathrm{DC}}\right)$. Under an applied electric field, the flame spread rate (FSR), flame width, leaning direction of the interacting twin flames varied substantially with varying the voltage and wire gap. The flame spread rate was initially larger for the wire with negative voltage (spreading flame with negative charge; $\mathrm{SF}-$ ) than the wire with positive voltage $(\mathrm{SF}+)$, but the two eventually became the same in the developed region when a quasi-steady state was reached. The FSR behavior could be classified into two regimes; twin flame spread (regime I) and single flame spread (regime II) after the extinction of SF+. Under regime I, three sub-regimes were identified depending on the wire gap and voltage. For the twin flame spread, the flame spread rate initially decreased with increasing voltage as the flame leaned toward the burnt wire. As the two flames interacted, the flame spread rate increased because of the ionic wind effect, and eventually decreased because of the loss of molten PE mass and the electrospray phenomenon. In regime II after the extinction of SF+, the single flame spread showed a transient behavior since the influences of electric field from burnt and unburned wire sections of SF+ wire varied with flame spread. When the voltage was increased even further, SF- was extinguished by streamer generation and, at excessive voltages, an electrical short occurred. The flame spread rates for twin flame spread were best correlated with the electric field intensity in the form of $\left|V_{\mathrm{DC}}\right|^{0.91} / S^{0.72}$.
\end{abstract}

(c) 2019 The Combustion Institute. Published by Elsevier Inc. All rights reserved.

\section{Introduction}

Unexpected arcing, short circuiting, and/or overheating of an electrical wire can lead to the ignition of combustible insulation materials and thus present a substantial risk of fire outbreak. Indeed, electrical wires are one of the main sources of fires in buildings and households, as well as in closed environments such as aircraft and spacecraft. Examples include the arc-initiated fires that occurred in the Swiss Air [1] and Mir Space Station [2] accidents, which resulted in fatalities. Thus, the fundamental characteristics of wire fires have been studied extensively, with respect to wire properties and parameters as insulation material, material thickness, external heating, ambient flow, and pressure [3-13].

Fire safety in space has also been studied extensively considering gravity effect [14-17]. Electrical wires for use in spacecraft are tested and evaluated using the NASA fire safety code [18], by measuring the upward flame spread over an inclined electrical wire under the ambient condition. An interaction among spreading

\footnotetext{
* Corresponding authors. Park).

E-mail addresses: Min.Cha@kaust.edu.sa (M.S. Cha), jeongpark@pknu.ac.kr (J.
}

flames over three parallel wires under a microgravity condition has been recently reported, emphasizing the role of flame interaction in realistic scenarios [19]. However, these studies do not consider the effect of electric field applied to the wire(s). When an electrical wire catches on fire due to an electrical short, the wire can still be under the influence of the electric field as an open circuit. In such cases, charged particles generated through chemi-ionization and subsequent ion chemistry in the reaction zone of the spreading flame, can be influenced by the electric field via the Lorentz force [20]. The transfer of momentum from accelerated charged particles to neutral molecules could generate a bulk flow by the ionic wind effect.

A limited number of studies have been conducted on the effect of electric fields on a spreading flame over electrical wires [21-24], and has shown that a spreading flame over electrical wires that were either inclined [23] or installed horizontally $[21,22,24]$ was sensitive to the alternating current (AC) electric field applied to the wire. These studies showed that when AC electrical fields were applied to polyethylene (PE)-insulated electrical wires, several molten-PE-related phenomena were observed. For example, one study described how a fuel-vapor jet was ejected from the surface of molten insulator and an internal circulation within the molten PE could be developed due to a Marangoni convection 


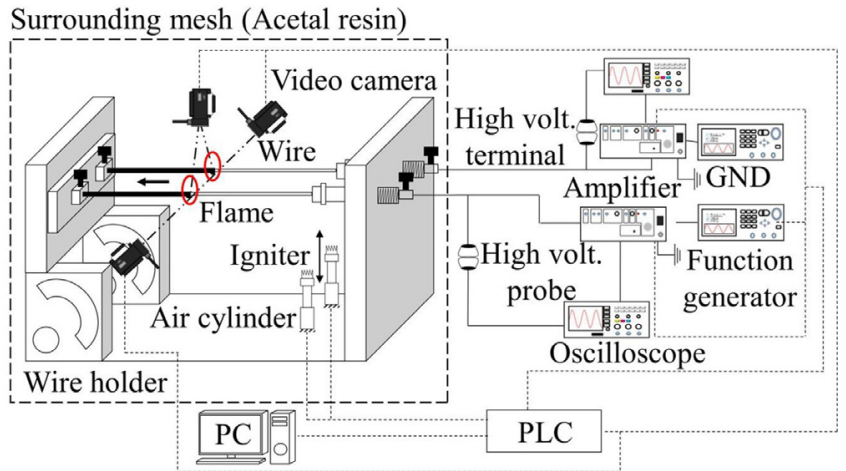

Fig. 1. Schematic of experimental setup.

[22]. The formation of a globular molten PE in front of a downward spreading flame led to the extinction of the flame, while multiple small droplets from the main flame were ejected due to an electrospray phenomenon $[23,24]$. Such phenomena can be important when judging the safety of an electrical wire, especially in cases, for example, when outdoor power lines with several hundred kVs cross forested and agricultural areas via a transmission tower, presenting a high risk of widespread fire $[25,26]$. A spacecraft is designed to supply power for analyzers, spectroscopes, and cameras with DC voltages of $\sim 5 \mathrm{kV}$ and even $15 \mathrm{kV}$ for space borne radar systems used for ground observations [27]. Whereas previous studies have examined flame spread over a single electrical wire only [3-17,21-24], most electrical wiring involves paired wires with various electrical potentials.

In this work, we study flame spread over twin electrical wires with direct current (DC) electric fields applied to suppress time varying potential in $\mathrm{AC}$, and we describe in detail the interaction between two spreading flames. Note that DC has minimal effect on flame spread for the single wire configuration [21-24], however as will be shown later, DC has significant effect for the present twin wire configuration. We used PE insulated electrical wires because these types of wires have been investigated extensively for understanding the fundamental physics of wire fires [3,5,3-17,21-24]. Here, we report data on the flame spread rate (FSR) along with several interesting features, including flame extinction, the electrospray and di-electrophoresis phenomena, streamer generation, and electrical shorts.

\section{Experiment}

The apparatus consisted of twin electrical wires and a wireholder, electrical power supplies, and a visualization setup, as schematically shown in Fig. 1. We used a PE-insulated electrical wire with diameter of $0.8 \mathrm{~mm}(0.5 \mathrm{~mm}$ diameter nichrome core) and $216 \mathrm{~mm}$ in length. The initial $70 \mathrm{~mm}$ from one end of the wire and the final $10 \mathrm{~mm}$ from the other end were excluded in data analyses because of the ignition transient and also to avoid interaction between the wire and the wire-holder. This left $136 \mathrm{~mm}$ of wire length available for our flame spread experiments. The twin wires were installed horizontally on a wire holder (with holes at $2 \mathrm{~mm}$ intervals), made of non-conductive acetal resin. For each wire, one end was attached to a fixture and the other end was connected to a spring to prevent bending due to thermal expansion during flame spread. The twin wires and holder were surrounded by an acetal mesh screen $(90 \times 90 \times 90 \mathrm{~cm})$ to prevent any influence from outside disturbances.

We ignited the twin flames using two hot-wire igniters $(1 \mathrm{~mm}$ in diameter, $\mathrm{Rh} / \mathrm{Pt} 13 \%$ ), which were placed on two air cylinders. To minimize the interaction between the ignition system and applied electric fields, the igniters were retreated away after igni- tion. A programmable logic controller was utilized to control the time sequences of experiment. First, electrical power was supplied to the igniter for $8 \mathrm{~s}$. After ignition, the air cylinders were activated to move the igniters away. Then, the DC power supplies were turned on with specified DC voltages. Three video cameras were triggered to capture images of the flame spread, and the recorded images were analyzed using a Matlab-based code. We performed five trial measurements of the behavior of the flame spread, and flame spread rate results presented here are the mean values with error bars. We captured close-up images with backlight illumination to visualize the behavior of the molten PE.

Two DC power supplies (Trek, 10/10B-FG) were used to apply positive and negative electric voltages, to obtain a large potential difference between the two wires. The applied voltage $\left( \pm V_{\mathrm{DC}}\right)$ was varied over the range $0-10 \mathrm{kV}$ and monitored using an oscilloscope fitted with a 1000:1 probe. One end of each wire was connected directly to the high-voltage terminal of a power supply and the other terminals of the power supply was connected to the building ground, thus giving an open circuit configuration. The gap distance $(S)$ between the two wires and the applied voltage were varied.

\section{Results and discussion}

\subsection{Overall flame spread behavior}

Figure 2 shows images of spreading flames under varying applied DC voltage $\left( \pm V_{\mathrm{DC}}\right)$ for a wire gap of $S=51 \mathrm{~mm}$, along with a baseline case where no electric field was applied. The images were taken at a range of $X=170-206 \mathrm{~mm}$ from the ignition point, except for the cases with 7 and $8 \mathrm{kV}$, which will be explained later.

For the baseline case, the twin flames spread in parallel and have a nearly vertical orientation to the wire, due to the buoyancy effect of burnt gas. At $\pm 1 \mathrm{kV}$, the spreading flame with positive (negative) voltage, hereafter called $\mathrm{SF}+(\mathrm{SF}-)$, leans toward the burnt wire. At $\pm 2.5 \mathrm{kV}, \mathrm{SF}+$ leans toward the unburned wire and tilts toward SF-. SF- elongates appreciably in the horizontal direction and the molten PE of SF- drips onto the ground. At $\pm 3.5 \mathrm{kV}, \mathrm{SF}+$ leans closer towards SF-. SF- becomes smaller and fine droplets are ejected from the molten PE surface [see the movie in Supplementary material (SM) 1], as marked with the red circle in Fig. 2. This process can be attributed to the electrospray phenomenon, which has been observed previously for single-wire experiments [23]. A small droplet simultaneously detaches from the main body of molten PE and moves toward the burnt wire [SM 1], driven by the di-electrophoresis phenomenon [24]. Fine droplets are then subsequently emitted from the detached droplet surface as a result of the electrospray phenomenon. From the top view for $V_{\mathrm{DC}} \leq \pm 3.5 \mathrm{kV}, \mathrm{SF}+$ is always tilted toward SF-, while SF- fluctuates in an unstable manner. The underlying mechanism of the flame tilting based on an ionic wind effect is discussed later.

At $V_{\mathrm{DC}}= \pm 4 \mathrm{kV}, \mathrm{SF}+$ is extinguished because the flame is highly stretched (by ionic wind) toward SF- [SM 2], while SF- once again leans toward the burnt wire, without any dripping of molten PE. $\mathrm{SF}$ - expands in size up to $\pm 6.0 \mathrm{kV}$ (with the dripping of molten $\mathrm{PE}$ ) and then decreases at $\pm 6.5 \mathrm{kV}$ (with no dripping of molten PE). Again, SF- leans toward the burnt wire at $\pm 6.5 \mathrm{kV}$. At $V_{\mathrm{DC}}= \pm 7 \mathrm{kV}$, SF- is extinguished within $22 \mathrm{~mm}$ of the ignition point, i.e., during the ignition transient. The inset photo at $t=0.55 \mathrm{~s}$ shows that small drops of molten PE (red circle) detaches continuously from the main body of molten PE, again due to di-electrophoresis phenomenon [24]. Finer droplets are subsequently ejected from the detached molten PE as a result of electrospray [23,24]. Owing to the lack of molten PE, the flame is extinguished at $t=2.97 \mathrm{~s}$ [SM 3]. The details will be explained later. For $V_{D C} \geq 8 \mathrm{kV}$ [SM 4], streamers are generated and $\mathrm{SF}+$ is first to be extinguished due to a large flame stretch toward SF-. SF- subsequently experiences 


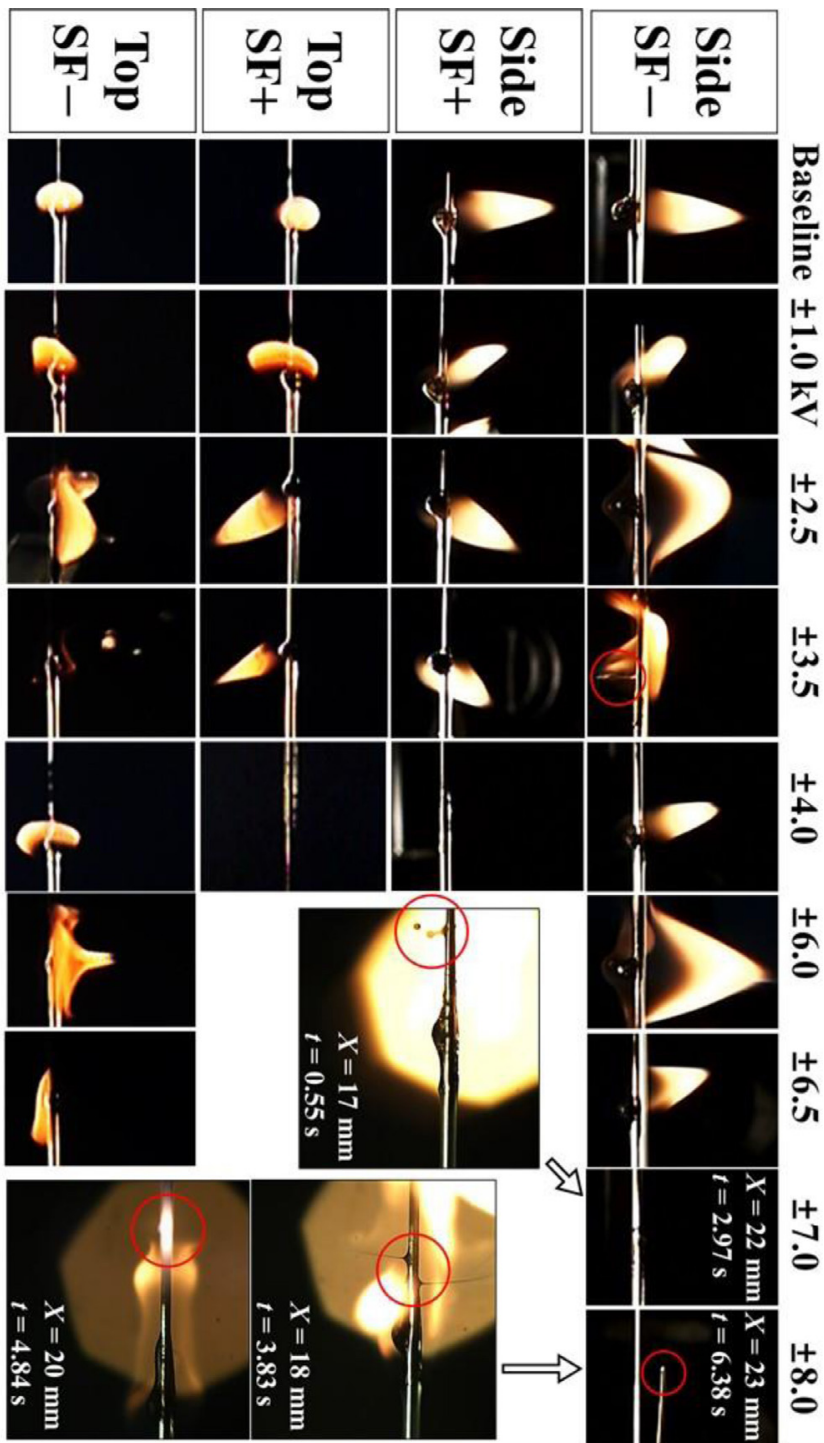

Fig. 2. Direct images of spreading twin flames with varying DC electric fields for $S=51 \mathrm{~mm}$. (For interpretation of the references to color in this figure, the reader is referred to the web version of this article.)

excessive loss of molten PE via electrospray and di-electrophoresis (red circles in inset photos). The repetitive generation of streamers between the two wires ultimately leads to breaking of the wire in SF-.

We produced a flame stability map based on our observation by varying $V_{\mathrm{DC}}$ and $S$, as shown in Fig. 3. Three regimes of flame spread were identified: both SF+ and SF- spread with no extinction in regime I; SF+ is extinguished while SF- keeps on spreading in regime II; SF+ is extinguished and subsequently SF- is also extinguished in regime III. When $S$ increases, these regimes are extended to higher voltages. Further increases in $V_{\mathrm{DC}}$ in regime III cause the wire to break by an electrical short for SF-.

Note that when we applied DC electric fields to spreading flames over single electrical wire with $\mathrm{NiCr}$ core, overall flame spread behaviors such as flame spread rate and flame shape and/or flame-leaning changed very little. While flame spread behaviors changed drastically for spreading flames over single electrical wire with applied AC electric fields [21-24]. This implies that the difference between flame spread behaviors with DC and AC electric fields applied to single electrical wire could be appreciable. Similarly, DC and AC electric fields could influence flame spread behav-

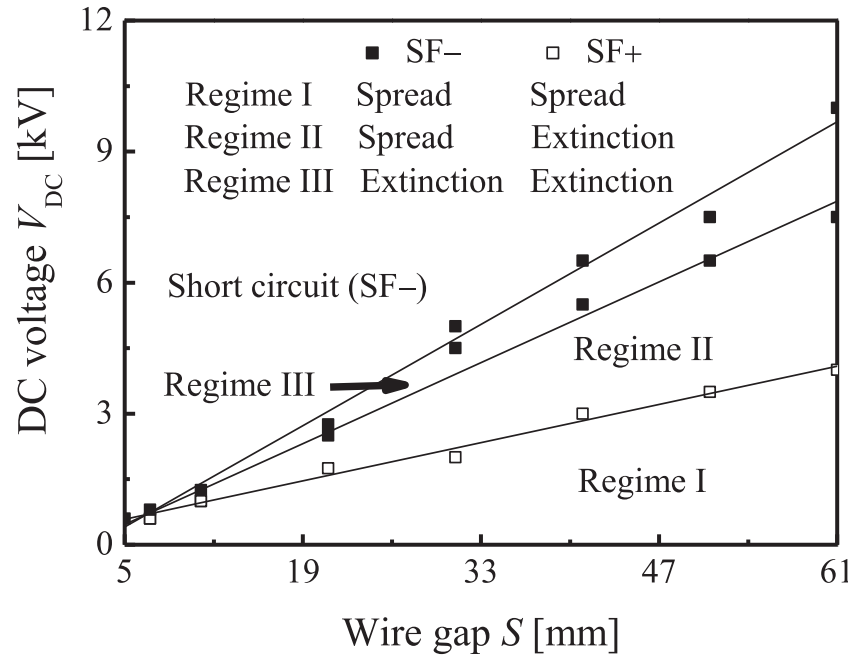

Fig. 3. Flame stability map in terms of wire gap and DC voltage.

iors for twin wire configuration and AC effect on twin flame spread will be a future work.

Soot particles can form on the fuel side of a flame, and their transport is influenced by the thermophoretic force caused by the temperature gradient between the flame and the molten PE or wire as well as the electrostatic force. These particles can be transported inward and deposited onto the molten PE or wire [21-24]. As shown in Fig. 2, the color of molten PE becomes darker due to significant deposition of soot as the applied voltage increases. This soot deposition could affect the radiation heat transfer, thereby enhancing the heat transfer to the molten PE, which subsequently affects the melting rate of PE. Sufficiently large molten PE formation could promote dripping of molten PE at -2.5 and $-6.0 \mathrm{kV}$ for SF-. This behavior is similar to that observed previously for a single wire with applied AC electric fields [21-24].

To demonstrate the importance of the interaction between the two flames, we first examine changes in the flame front position $\left(X_{\mathrm{f}}\right)$ and the angle $\theta_{1}\left(\theta_{2}\right)$ between the $\mathrm{SF}+$ wire and the line connecting the flame front positions of SF+ and SF- (between the SF+ wire and the tilting direction of SF+ flame toward SF-) with time ( $t$ ) for $S=51 \mathrm{~mm}$ with \pm 2.5 (Fig. $4 \mathrm{a}$ ) and $\pm 3.5 \mathrm{kV}$ (Fig. $4 \mathrm{~b}$ ). The angles are marked by yellow and white lines in the inset photo of Fig. 4a. Here, we define the flame front position as the position of the outermost edge of the flame in contact with the unburned wire. Time zero is defined when the flame reaches $X_{\mathrm{f}}=70 \mathrm{~mm}$ from the ignition point. Here, "single" denotes single-flame spread (by igniting only one wire) and "twin" means twin-flame spread (by igniting both wires) with the same DC potentials applied to twin wires.

For the single-flame spreads with 2.5 (Fig. 4a) and $3.5 \mathrm{kV}$ (Fig. $4 \mathrm{~b}$ ), the flame positions over time are nearly equal, irrespective of the positive and negative wires, implying a minimal influence of the electric field. For the single-flame spreads with $6.0 \mathrm{kV}$ (Fig. 4c), SF- spreads faster than SF+, while SF- spreads slightly slower than the SF- of the twin-flame spread. The details will be explained later. In comparison, for the twin-flame spread for 2.5 and $3.5 \mathrm{kV}, \mathrm{SF}$ - initially spreads faster than SF+ over time $\left(X_{\mathrm{f}}<\right.$ $165 \mathrm{~mm}$ ) and the two flames then spread with equal spread rates, giving the same slopes on $X_{\mathrm{f}}-t$ plot (Fig. 4). The results also show that $\theta_{1}\left(\theta_{2}\right)$ becomes nearly constant for $X_{\mathrm{f}}>165 \mathrm{~mm}$. This behavior implies that the twin-flame spread initially exhibits a transient behavior (the developing region) and reaches a quasi-steady state (the developed region) over a critical flame front position. 

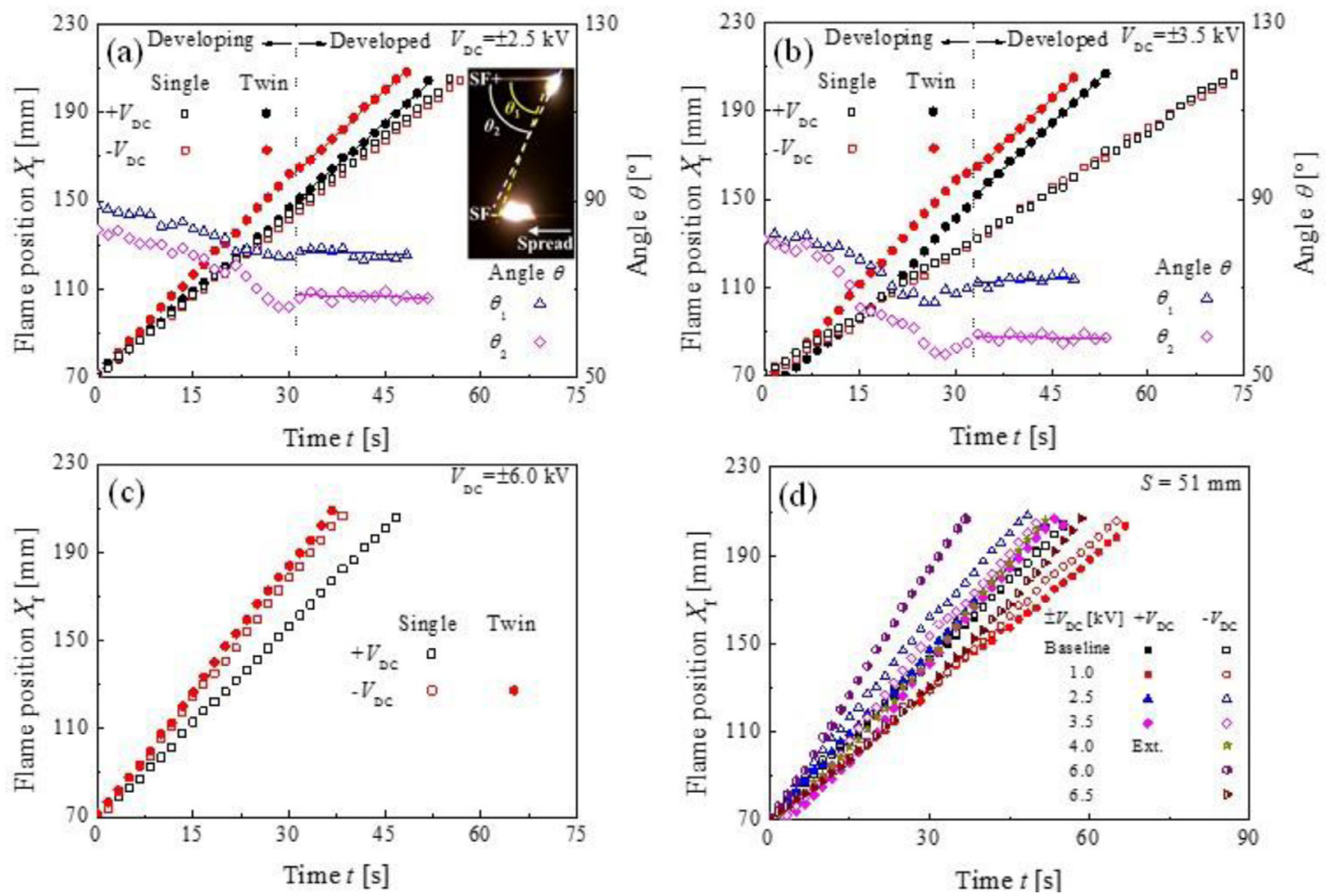

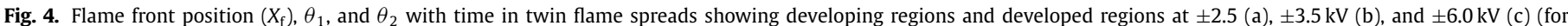

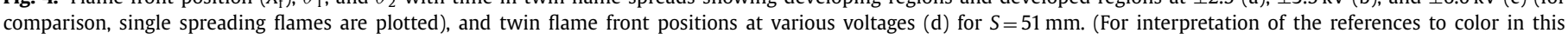
figure, the reader is referred to the web version of this article.)

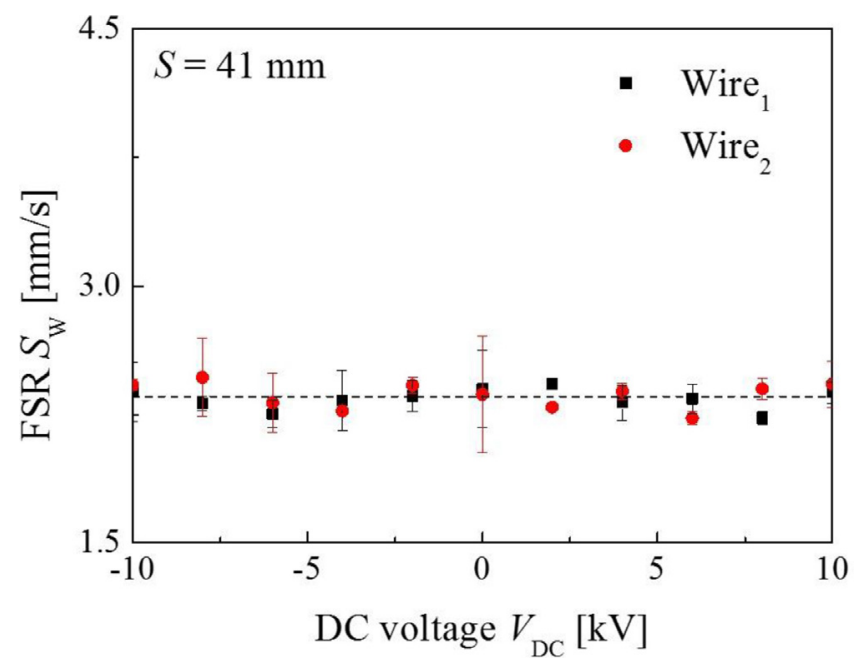

Fig. 5. Flame spread rate in the cases of applying the same DC voltages to twin wires.

Figure $4 \mathrm{~d}$ shows the twin-flame spreading behavior at various voltages for $S=51 \mathrm{~mm}$. In all cases, SF- and SF+ spread reasonably linearly with time in the developed regions. Thus, a quasisteady twin-flame spread rate (FSR, $S_{\mathrm{w}}$ ) can be determined from $S_{\mathrm{w}}=d X_{\mathrm{f}} / d t$ in the developed region, as discussed below.

\subsection{FSR with electric fields}

Here, we first examine cases where we apply the same DC voltages to the two electrical wires. The flame spread rates with $V_{\mathrm{DC}}$ for $S=41 \mathrm{~mm}$ are shown in Fig. 5. Negative (positive) DC voltage denotes that the same negative (positive) DC voltages are applied to the two electrical wires. The zero voltage corresponds to the baseline case with no applied electric field. The result shows that FSRs are minimally affected by the electric fields similarly to that of the baseline case $(2.35 \mathrm{~mm} / \mathrm{s})$. This verifies that the FSRs are not influenced when there is zero electric potential difference between the two wires.

As mentioned previously, SF- and SF+ spread at the same rate in the flame front positions in the developed region. Figure 6 shows the flame spread rate with $V_{\mathrm{DC}}$ at various wire gaps, where a mean FSR was obtained from five trials and standard deviation is marked as error bar. Here, Ext+ (Ext-) refers to the extinction of SF+ (SF-). When a DC electric field is applied, the FSR initially decreases with $V_{\mathrm{DC}}$ such that $S_{\mathrm{w}}<S_{\mathrm{w}, 0}$ for a fixed wire gap, where $S_{\mathrm{w}, 0}$ indicates the baseline condition with no applied electric field.

The behavior of the FSR for $S=61 \mathrm{~mm}$ (Fig. 6f) is the representative of the overall behavior across most values of $S$. The FSR initially decreases with $V_{\mathrm{DC}}$, increases sharply, and then decreases again until $\mathrm{SF}+$ is extinguished at $V_{\mathrm{DC}}=4 \mathrm{kV}$. After the extinction of $\mathrm{SF}+, \mathrm{SF}$ - corresponds to a single flame propagation where FSR decreases, increases beginning at $5 \mathrm{kV}$ to a maximum at $7 \mathrm{kV}$ and then decreases to extinguish. Note that the single-flame propagation mode of SF- may be influenced by the relative distance from the location of the SF+ extinction since electric field intensity varies across the burnt and unburned wire. Thus, the flame spread could be transient in nature. The FSR data for SF- after the extinction of SF+ shown in Fig. 6 represent during the short period just after the extinction of SF+. This point is further clarified later. As the DC voltage increases even further, SF- is also extinguished during propagation. As the voltage further increases, the wire for SFis broken by a short circuit during the initial transient period due to the generation of an excessively strong streamer. Note the short circuit occurs at flame front positions say less than $30 \mathrm{~mm}$ from 

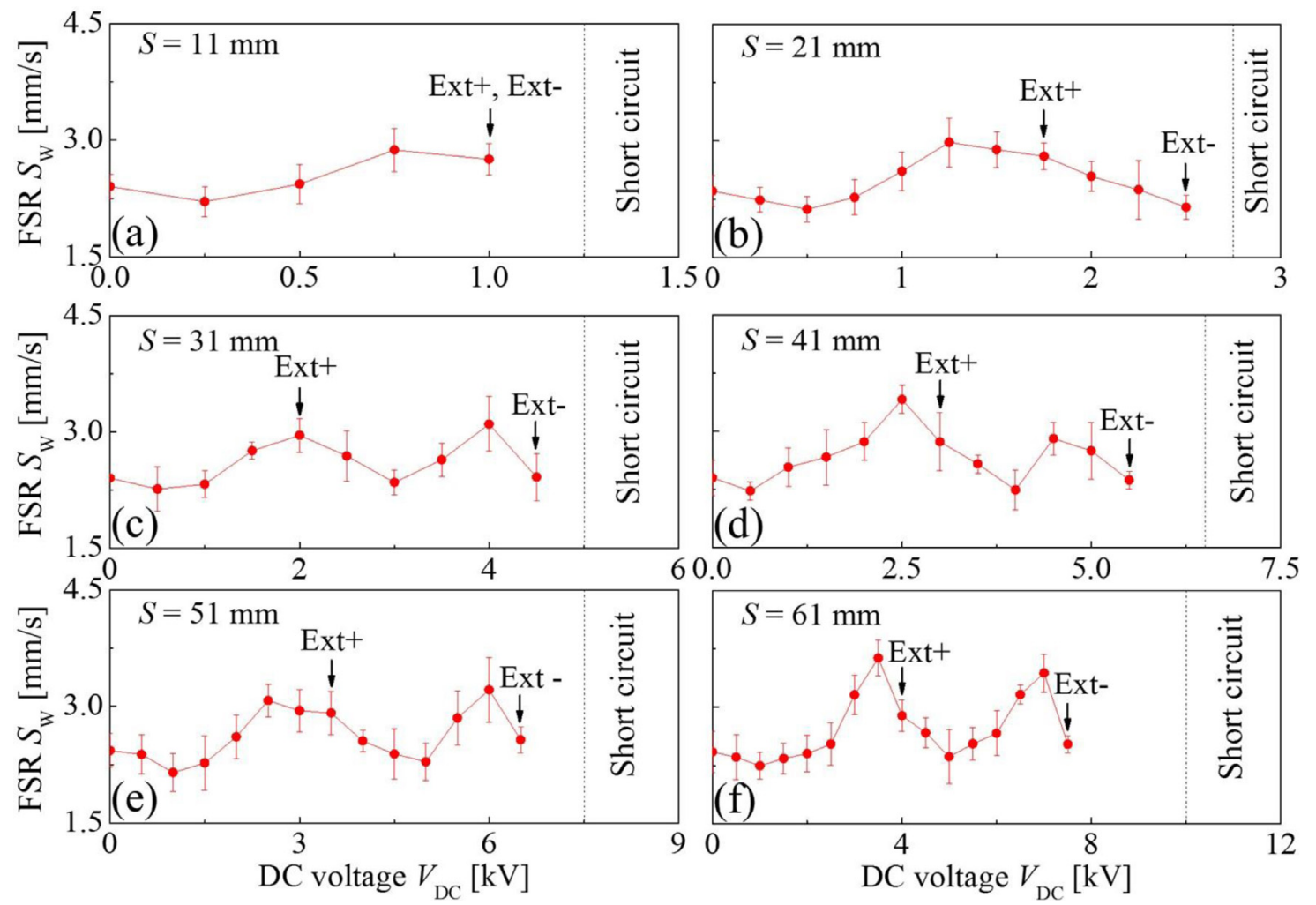

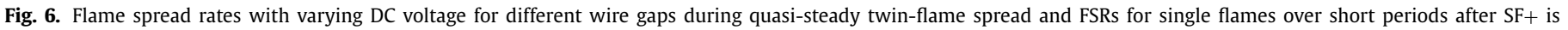
extinguished.

the ignition point (corresponding to an ignition transient period). This tendency for different wire gaps is maintained to $S=31 \mathrm{~mm}$ (Fig. 6c-e), while the voltage for flame extinction decreases gradually with the decrease in $S$. For $S=11$ and $21 \mathrm{~mm}$ (Fig. 6a and b), the FSR decreases, increases, and decreases again. For $S=11 \mathrm{~mm}$, $\mathrm{SF}+$ and SF- are extinguished simultaneously for $V_{\mathrm{DC}}>1.0 \mathrm{kV}$. The details on flame extinction and short circuits will be explained later.

As was shown in Figs. 4(a-c), the variation of flame positions over time were nearly equal for the single-flame spread under 2.5 and $3.5 \mathrm{kV}$ (Fig. 4a and b) irrespective of the positive or negative charge on the wire (i.e., a minimal effect of electric field without having flame interaction) whereas for $6.0 \mathrm{kV}$ (Fig. 4c), the single flame spread of SF- was initially faster than that of SF+. Recall that for twin-flame spread (Fig. 2 for $S=51 \mathrm{~mm}$ ), SF+ was extinguished at $V_{\mathrm{DC}}>3.5 \mathrm{kV}$. Subsequent flame propagation of SF- corresponded to a single-flame spread and this is transient in nature, as described previously.

To further elucidate the spreading behavior of the flames, single- and twin-FSRs of SF- are compared with DC voltage in Fig. 7 for $S=51 \mathrm{~mm}$. Here, for the single flame cases, core (PE) means that the positively charged wire is without (with) PE insulation. The results show that the FSR for SF- first decreases, increases, and then decreases again for both cases of core and PE, similar to the SF- after the extinction of SF+. However, the behaviors are quite different for $V_{\mathrm{DC}}>3 \mathrm{kV}$ depending on the presence of PE insulation on the positively charged wire. This implies that the FSR of SF- for the twin-flame case after the extinction of SF+ depends sensitively on the relative position of bare wire from the flame. Note that the data of FSR for SF- (Fig. 6) after the extinction of SF+ (FSR was measured for a brief period of time after the extinction of $\mathrm{SF}+$ ) contains a transient effect by the change in the relative position of $\mathrm{SF}$ - to the burnt wire position as the single flame of SF- spreads.

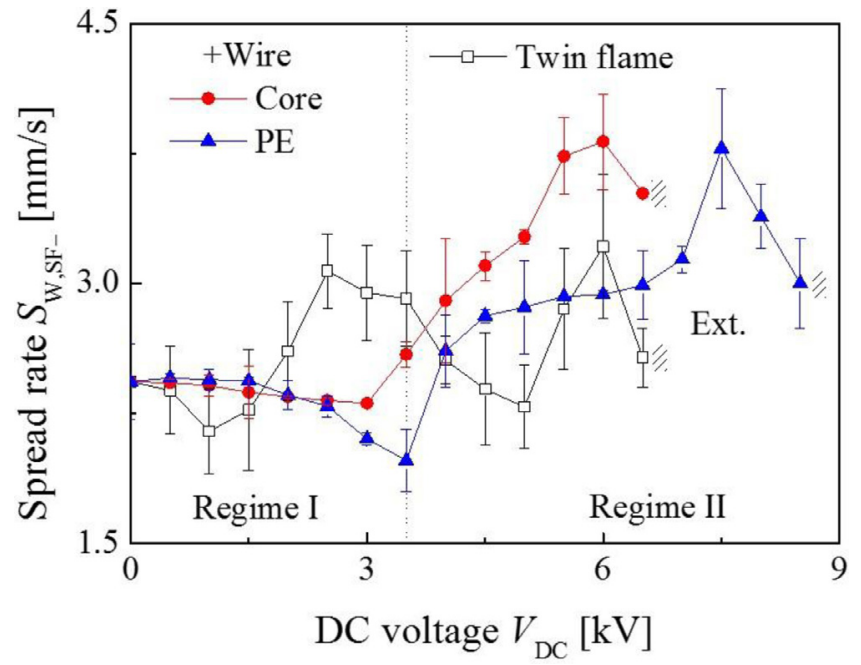

Fig. 7. Single- and twin-flame spread rates of SF- with DC voltage for $S=51 \mathrm{~mm}$. $\mathrm{PE}$ and core represent the non-burning positively charged wires with PE insulation and $\mathrm{NiCr}$ core only, respectively.

\subsection{Flame tilting, ionic wind, dripping, electrospray, and di-electrophoresis}

As was shown in Fig. 2, when the DC voltage was low, the flame leaned toward the bare-wire, such as $\pm 1 \mathrm{kV}$ for $S=51 \mathrm{~mm}$. This was due to the electric field intensity which, because of the presence of PE insulation, is stronger in the region of burnt bare wire compared to the unburned wire region. Such behavior has been reported for the single-wire cases [21-24], resulting in a reduction in the FSR because of the ineffective heat transfer to PE toward the unburned side $[9,10,21-24]$. 
As $V_{\mathrm{DC}}$ increases further, the twin flames begin to interact (see Fig. 2 at \pm 2.5 and $\pm 3.5 \mathrm{kV}$ ). As mentioned previously, charged particles are generated via chemi-ionization and subsequent ion chemistry in the reaction zone of a spreading flame. When an electric field is applied, these particles are accelerated via the Lorentz force. Upon collisions with neutral molecules, the momentum is transferred resulting in the generation of bulk flow of an ionic wind [20]. Since positive ions in a flame are more abundant than negative ions [20], due to the existence of electrons and charge neutrality, the bulk ionic wind is directed toward the negative potential. Further confirmation in measuring the concentration of charged ions with spatial resolution in a spreading flame can be a challenging work in the future. However, recent visualization of the ionic wind effect and modeling for gaseous fuels clearly demonstrated a stronger ionic wind by abundant positive ions [28,29].

At low voltage $( \pm 1 \mathrm{kV}$ in Fig. 2$)$, the leaning of the flame toward burnt wire reduces effective heat transfer to the unburned PE insulation, thus FSR decreases. Note that the direction of ionic wind along with the wire toward the unburnt wire, resembling a counter-current type of forced convection (flow direction opposed to spread direction) [30-32].

As the voltage increases, the electric fields between the two wires start to interact. The ionic wind in SF- is directed toward the center of the wire with negative potential such that the flame radius reduces, enhancing heat transfer to the unburned PE insulation. Consequently, the FSR increases with the voltage. The ionic wind from SF+ is pushed toward SF-. Initially, SF- propagates faster than $\mathrm{SF}+$ such that $\mathrm{SF}+$ leans toward the unburned $\mathrm{PE}$ insulation and thereby enhancing heat transfer to PE and increasing FSR. As the separation distance between SF+ and SF- increases, the SF+ leans more toward unburned wire section. Considering the ionic wind effect, this situation resembles a cocurrent flame spread (flow direction same as spread direction) [30-32] as if forced flow is directed from burnt to unburned wire, resulting in the increase in FSR of SF+. Finally, the two flames propagate with the same speed in the developed region. Note that ionic wind for SF- is pushed centrally toward its own wire, effectively heating the $\mathrm{PE}$ and causing it to melt, thereby increasing the spread rate. The competition between the outward flow caused by burning and the inward ionic wind can induce flame fluctuations. The ionic wind pushes SF+ toward the SF- wire, where the flame is stabilized. Thus, the flame experiences an effective blowing similar to a crosswind and this excessive blowing can ultimately extinguish $\mathrm{SF}+$ at high voltages (Ext+ in Fig. 6).

The behavior of the spreading flame becomes much more complex when we consider the behaviors of molten PE over the electrical wire when an electric field is applied. It has been shown previously [24] that unequal field forces (between the unburned and burnt wires) acting on molten PE for a single flame spread over an electrical wire with an AC electric field applied, can cause part of molten PE to migrate toward the region of higher electric field intensity (i.e., toward the bare wire). This phenomenon was attributed to a di-electrophoresis [33-43].

Figure 8 demonstrates several sequential images of $\mathrm{SF}-$ at $V_{\mathrm{DC}}=3.5 \mathrm{kV}$ for $S=51 \mathrm{~mm}$ [SM 1]. On the main body of molten $\mathrm{PE}$ for the negatively charged wire, negative ions/charges drift toward the liquid surface of the molten PE and positive ions drift away from the surface toward the wire. The accumulated negative ions/charges on the surface are concentrated on the outermost skin layer. The liquid surface can then be drawn out and forms a liquid Taylor cone. Fine droplets are subsequently emitted from the surface of molten PE in the form of an electrospray [23,24,44-47] [SM 1], as shown in the photo at $134 \mathrm{~ms}$. This behavior is similar to previous observations for a single-wire case [23,24]. At 40 and $64 \mathrm{~ms}$, a small droplet is detached from the main body of molten $\mathrm{PE}$ and moves toward the burnt wire due to di-electrophoresis phenomenon [24]. A Taylor cone on the detached molten PE surface also forms at $64 \mathrm{~ms}$ and an electrospray generates. As the DC voltage increases in the twin-wire flames, the molten PE becomes darker, such as at $\pm 2.5 \mathrm{kV}$ in Fig. 2 for example. Soot particles formed in the fuel region of the spreading flame are transported and deposited on the wire and/or in the molten PE through thermophoresis and/or electrophoresis. The soot deposition increases with increasing DC voltage, leading to the radiation absorption to the molten PE. Sufficient accumulation of molten PE by enhanced melting of PE may result in a dripping of molten PE. This behavior is similar to that observed in a spreading flame over a single (horizontal and inclined) electrical wire when an AC electric field is applied with high frequencies and/or high voltages [21-24]. Note that di-electrophoresis increases surface area of molten PE, enhancing evaporation rate, thus FSR. While electrospray and molten PE dripping induce the loss of molten PE without contributing thermal feedback, thus reducing FSR. Apparently, the effect of electrospray and dripping are more pronounced in decreasing FSR at high voltages.

\subsection{Flame spread rate correlations}

The overall behavior of the relationship between flame size and FSR over a twin-wire is investigated when DC voltages are applied. Note that the size of flame in heterogeneous combustion (such as a droplet or candle flame) in general reflects the burning rate reasonably well [21-24]. The flame width $W$ with DC voltage is shown in Fig. 9 for $S=51 \mathrm{~mm}$, where $W$ is defined as the length along the wire between the outer edges of the flame along the burnt and unburned wire, as marked in the inset photo in Fig. 9. The average width was determined over $X=170-206 \mathrm{~mm}$ from the ignition point and the error bars denote the standard deviations with a maximum value of $1.43 \mathrm{~mm}$. The qualitative trend in the flame width with DC voltage is similar to that of the FSR, emphasizing the role of flame size in controlling the spread rate.

Considering the important role of the dynamic behaviors of molten PE on the FSR, the regime diagram presented in Fig. 3 is further analyzed. The dripping and electrospray phenomena lead to a loss of molten PE, thus influencing the FSR. The dielectrophoresis effect elongates the molten PE along the wire and increases the surface area of the molten PE. Based on the occurrences of dripping (DP), electrospray (ES), and di-electrophoresis (DEP), regimes I and II can be further divided into three subregimes based on the behavior of SF- in terms of DC voltage and wire gap, as shown in Fig. 10. Here, NDP denotes no dripping of molten PE.

The behavior of the molten PE during flame spread are presented in SM 5 with DC voltage for $S=51 \mathrm{~mm}$. The result indicates that the sub-regimes I-1, I-2, and I-3 correspond to NDP, DP, and simultaneous occurrence of ES+DEP, respectively. The sub-regimes II-1, II-2, and II-3 after the extinction of SF+ correspond to NDP, $\mathrm{DP}$, and then NDP again, respectively. In this case, the simultaneous occurrence of ES+DEP appears during the transient extinction of SF- at high voltages.

The normalized FSR of $S_{\mathrm{w}} / S_{\mathrm{w}, 0}$ is analyzed further based on the observed behavior of molten-PE. Since the flames with applied electric fields are influenced by electric field intensity $|E|$ [24], FEMM 2.4 software [48] was used to determine $\left|E_{\mathrm{DC}}\right|$ between two wires on the plane passing through the centers of the wires. A typical profile $\left|E_{\mathrm{DC}}\right|$ with and without $\mathrm{PE}$ insulation is shown in SM 6(a) for $S=61 \mathrm{~mm}$ where $Y$ is the distance from centerline of the plane.

In an electrical wire fire, the flame edge at the outer surface of unburned PE could influence the flame spread rate appreciably, where a local quenching leads the flame edge to be partially premixed and to have propagation characteristics [49]. Thus, the 

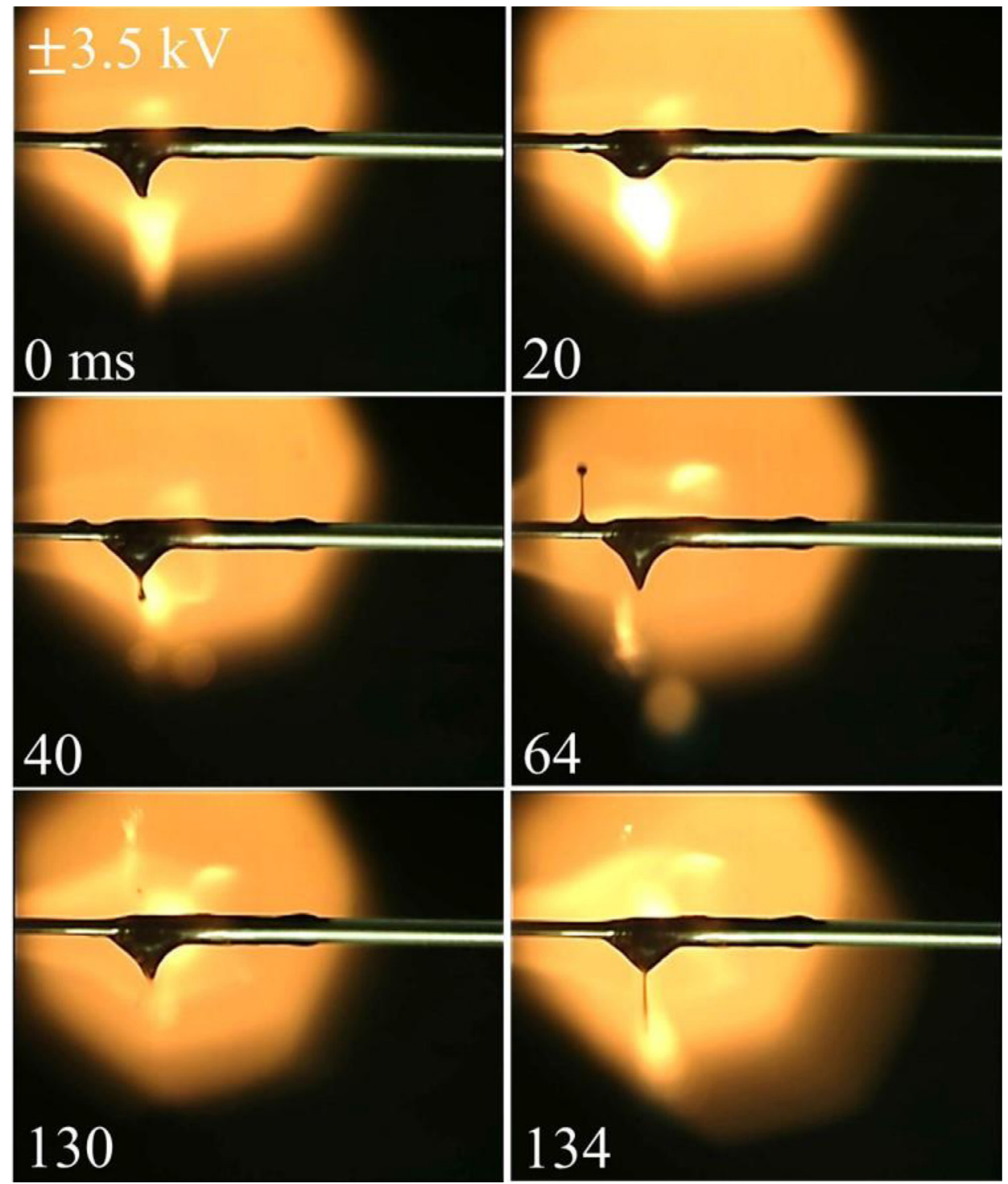

Fig. 8. Sequential images of SF- and the simultaneous occurrence of di-electrophoresis and electrophoresis at $\pm 3.5 \mathrm{kV}$ for $S=51 \mathrm{~mm}$ (see $\mathrm{SM} 2 \mathrm{for}$ movie).

electric field intensity at the outer surface of the PE insulator is correlated with the experimental parameters of the applied voltage $V_{\mathrm{DC}}$ and wire gap $S$. The best correlation is found as $\left|E_{\mathrm{DC}}\right|$ $[\mathrm{kV} / \mathrm{mm}]=0.0032 \times\left|V_{\mathrm{DC}}\right|^{0.91} / S^{0.72}\left[\mathrm{kV}^{0.91} / \mathrm{mm}^{0.72}\right]$ with a correlation coefficient of $R=0.99$ as shown in SM 6b.

We plotted the normalized FSR, $S_{\mathrm{w}} / S_{\mathrm{w}, 0}$, in Fig. 11 as a function of $\left|V_{\mathrm{DC}}\right|^{0.91} / S^{0.72}$, representing the electric field intensity at the outer surface of PE, with representative inset photos. We provide the raw data as Table SM-8 to be potentially used for future modeling works. SF- leans toward the burnt wire in sub-regime I-1 because the electric field intensity in the bare wire side is larger than that in the unburned wire $(-1 \mathrm{kV}$ in SM 5) [21-24]. No dripping of molten PE occurs in this sub-regime I-1. The decrease in FSR is attributed to the ineffective heat transfer from the flame to the PE on the unburned side by the leaning of the flame toward the burnt side. The flame size (height and width) of SF- becomes larger when the dripping of molten PE occurs in the sub-regime $\mathrm{I}-2(-2.5 \mathrm{kV}$ in SM 5 and Fig. 11), where the FSR increases with increasing (decreasing) voltage (wire gap). This implies that the effect of flame size in the FSR is much more dominant than that of mass loss from dripping of molten $\mathrm{PE}$, as observed previously for a single flame spread [24]. Note that when dripping occurs, the burning behavior is inherently intermittent. However, the flame persists long enough to allow the FSR to be determined during the active burning phases compared to the dripping intervals. In subregime I-3 (-3.5 kV in SM 1, SM 5, and Fig. 11), detached droplets (via di-electrophoresis) from the main body of molten PE burn out quickly while the loss of mass from the main body of melting PE as a result of electrospray becomes significant. This gradually leads to a reduction in flame size and thereby eventually decreases FSR.

Concerning the electric field intensity correlation above, when the geometry (wire and insulation diameters) or material (permittivity) changes, a similar correlation is expected to hold (with potential modifications of the exponents to $V_{\mathrm{DC}}$ and $S$ as shown in Fig. SM6b), however, details should be a future work.

As shown in Fig. 7, qualitative behaviors of single-flame spread rates after the extinction of SF+ and twin-flame spread rates were similar, exhibiting decreasing, increasing, and decreasing again with $V_{\mathrm{DC}}$. Even for single-flame spread, the behavior of SF- indicates the similar features observed in regimes II-1 (NDP), II-2 (DP), and II-3 (NDP) and simultaneous occurrence of ES+DEP prior to flame extinction in Fig. 10 (SM 7 for movies). One exception is for the single-flame spread of SF-, where a short circuit does not occur up to $10 \mathrm{kV}$. This corresponds to the limit of the power supply 


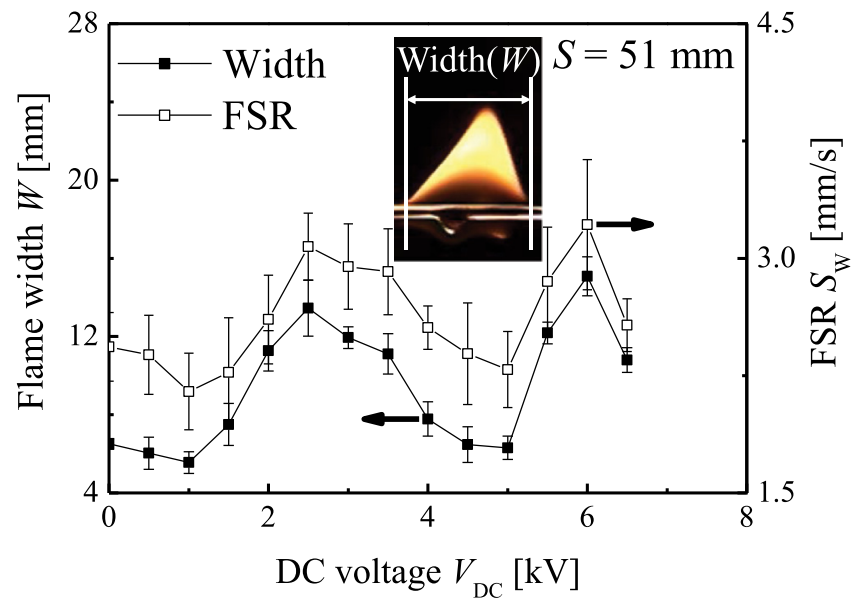

Fig. 9. Flame width and flame spread rate with increasing applied voltage for $S=51 \mathrm{~mm}$.

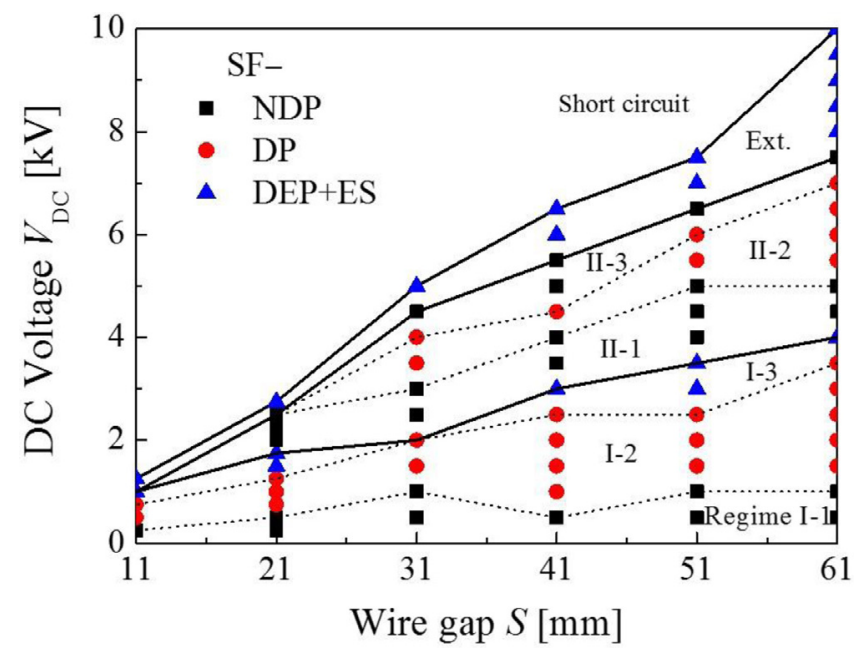

Fig. 10. Regime diagram based on the dynamic behaviors of molten PE in terms of DC voltage and wire gap (NDP; no-dripping, DP; dripping, DEP; di-electrophoresis, ES; electrospray, and Ext; transient extinction in the developing region).

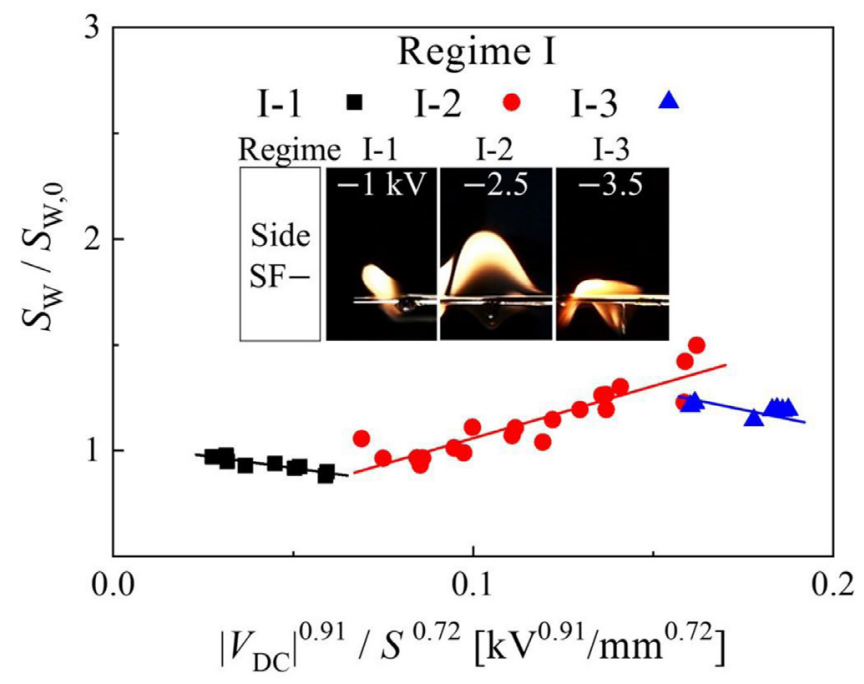

Fig. 11. Correlations of normalized flame spread rate in terms of electric field intensity represented by $\left|V_{\mathrm{DC}}\right|^{0.9} / S^{0.7}$. while the regime of simultaneous occurrence of ES+DEP (prior to flame extinction) is extended to $10 \mathrm{kV}$.

The best correlations obtained for the sub-regimes are as follows; $S_{\mathrm{w}} / S_{\mathrm{w}, 0}=-2.35 \times\left|V_{\mathrm{DC}}\right|^{0.91} / S^{0.72}+1.04$ with $R=0.92$ in sub-regime I-1 with $V_{\mathrm{DC}}$ and $S$ in [kV] and [mm], respectively; $S_{\mathrm{W}} / S_{\mathrm{W}, 0}=4.94 \times\left|V_{\mathrm{DC}}\right|^{0.91} / S^{0.72}+0.57$ with $R=0.90$ in sub-regime $\mathrm{I}-2 ; S_{\mathrm{W}} / S_{\mathrm{W}, 0}=-3.49 \times\left|V_{\mathrm{DC}}\right|^{0.91} / S^{0.72}+1.80$ with $R=0.96$ in subregimes I-3. It is worthwhile to mention again that FSRs in regime II are transient in nature after the extinction of $\mathrm{SF}+$ as explained previously. Thus, such data for flame spread rate in regime II were not included in Fig. 11 while these were presented for the regime diagram based on the dynamic behaviors of molten PE in Fig. 10. Although not shown here, we have further tested the behaviors of FSR with $V_{\mathrm{DC}}$ for a single flame spread of SF-, where positive voltages are applied to SF+ wire with one half of the wire being bare core and the other half being PE-coated wire and vice versa. In such cases, the transient behaviors of FSR with $V_{D C}$ in these tests are very complex.

\subsection{Flame extinction and short circuit}

In the previous section, we described how SF+ is pushed toward the negatively charged wire since the bulk ionic wind is directed toward the negative potential. In such situations, $\mathrm{SF}+$ experiences a blowing effect toward SF- from a cross-wind, leading to a marked stretch effect on $\mathrm{SF}+$, thus resulting in the extinction of $\mathrm{SF}+(\mathrm{SM} 2)$. In this section, we now focus on the flame extinction of SF- and short-circuiting.

At $7 \mathrm{kV}$ for $S=51 \mathrm{~mm}$ (SM 3a), a week streamer is generated and then both SF+ and SF- are enlarged momentarily because of the detachment of molten PE from the wire. Simultaneously, SF+ is extinguished before reaching the developed regime because of the stretch toward the $-V_{\mathrm{DC}}$ wire, while SF- survives with a small amount of molten PE and spreads. For better understanding, several sequential images of SF- extinguishing with the simultaneous occurrence of di-electrophoresis and electrospray are shown in Fig. 12 at $\pm 7.0 \mathrm{kV}$ for $S=51 \mathrm{~mm}$. SF-, with a relatively small flame size at first, loses significant amounts of molten PE detached from the main molten PE due to di-electrophoresis (see SM 3b), and the detached droplets subsequently lose mass via electrospray (at $0 \mathrm{~s}$ in Fig. 12). The flame size then increases momentarily and subsequently becomes smaller $(2.07 \mathrm{~s})$, thus restricting the formation of molten PE while small droplets continue to detach from the main body. This reduces the flame size further $(2.07-2.16 \mathrm{~s})$, ultimately leading to flame extinction at $2.93 \mathrm{~s}$. The sequential nature is the mechanism of flame extinction at high voltages for the regime III in Fig. 3.

At $8 \mathrm{kV}$ for $S=51 \mathrm{~mm}$, we observe similar processes to $7 \mathrm{kV}$ whereby a strong streamer is generated and $\mathrm{SF}+$ is extinguished (SM 4). A part of the bare wire of SF- is overheated by strong streamers (inset photo at $t=4.84 \mathrm{~s}$ in Fig. 2 and SM 4), which leads to the wire breaking because of a short circuit. This causes SF- to extinguish because the molten $\mathrm{PE}$ is removed by the violent motion of the wire when breaks.

The critical voltages for flame extinction and an electric short as a function of wire gap were shown in Fig. 3. The extinction voltages, $V_{\text {Ext,+ }}$ and $V_{\text {Ext,- }}$ for SF+ and SF-, respectively, both increased reasonably linearly with the wire gap. The best fits are $V_{\text {Ext, }}[\mathrm{kV}]=0.13 \times S[\mathrm{~mm}]-0.20$ with $R=0.99$ and $V_{\text {Ext, }+}[\mathrm{kV}]=$ $0.06 \times S[\mathrm{~mm}]+0.27$ with $R=0.99$. The critical voltage for an electric short $\left(V_{\text {short }}\right)$ also increases linearly with the wire gap. The best fit is $V_{\text {short }}[\mathrm{kV}]=0.17 \times S[\mathrm{~mm}]-0.42$ with $R=0.99$.

Ejection of a series of small droplet flames detached from the wire (due to the electrospray phenomenon) could pose a fire hazard because such small burning droplets can readily spread flames to neighboring electrical wires or other combustible mate- 

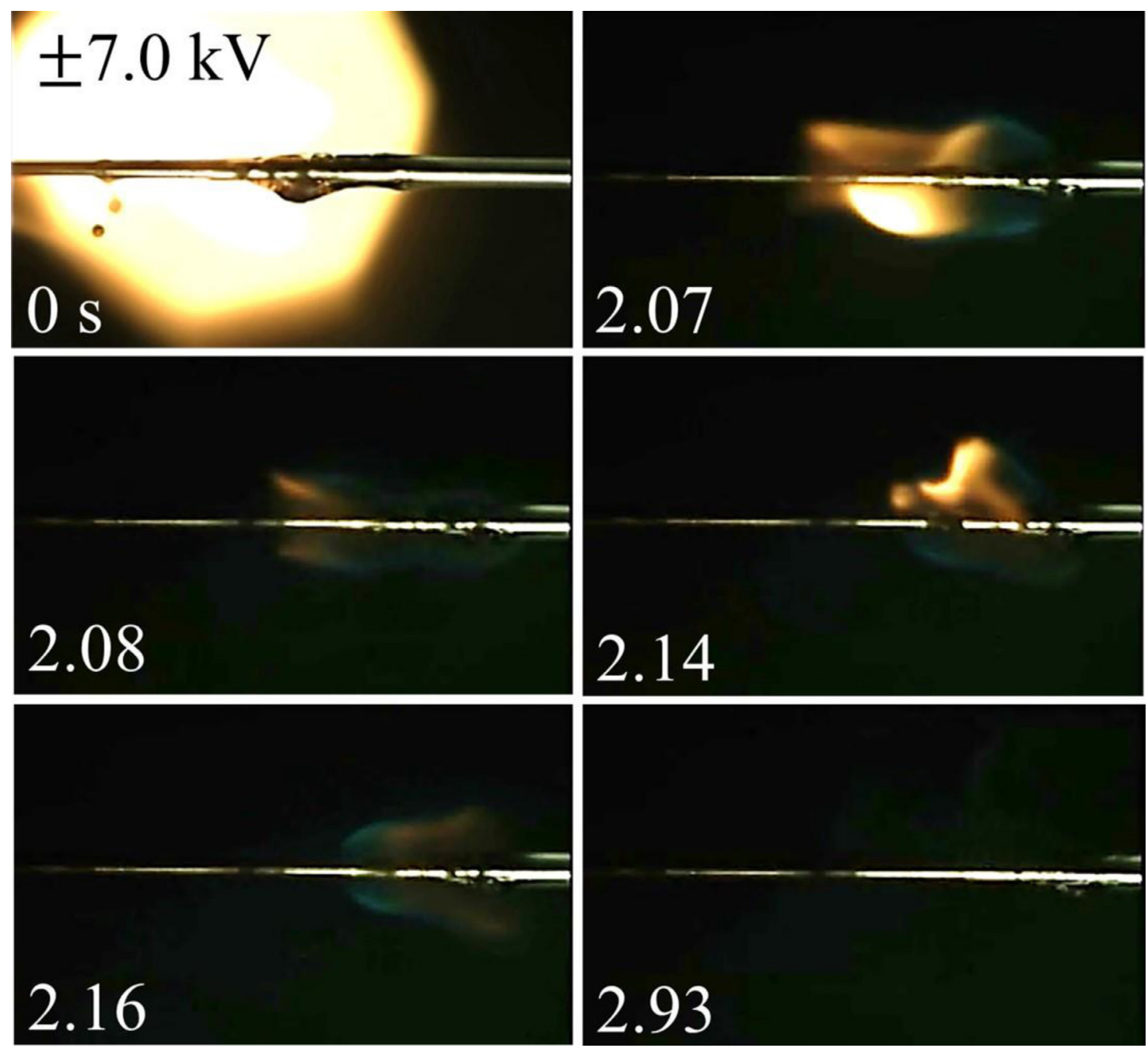

Fig. 12. Sequential images of SF- extinguishing with simultaneous occurrence of di-electrophoresis and electrospray at $\pm 7.0 \mathrm{kV}$ for $S=51 \mathrm{~mm}$ (see $\mathrm{SM} 3$ for movies).

rials, potentially leading to a much faster spread of fire. The existing NASA codes [18] does not consider the effect of an electric field on flame spread, including phenomena such as the modification of the spread rate via the interaction between twin wire flames, di-electrophoresis and electrospray. Note also that under a microgravity environment, the dripping phenomenon that we describe would not occur, further influencing FSR behavior. Furthermore, the electrospray phenomenon can be different under microgravity, as it can change the geometrical shape of molten PE when forming a Taylor cone allowing electrospray to occur. Future studies under microgravity are required to improve current testing standards for wire fires that occur in space.

\section{Concluding remarks}

The effect of a DC electric field on the characteristics of flame spread over polyethylene-insulated twin electrical wires was studied by varying the wire gap and voltage. The spread rate, flame width, leaning and tilting direction of interacting twin flames were appreciably modified by varying the voltage and wire gap when an electric field is applied. The flame spread rate of flames with a negative voltage (SF-) was larger than that with positive voltage $(\mathrm{SF}+)$ in the developing region but both the flame spread rates become equal in the developed region.
The FSR behavior can be classified into two regimes; twin flame spread and single flame spread after the extinction of SF+. For the twin flame spread case (regime I), three sub-regimes are identified based on $S$ and $V_{\mathrm{DC}}$. Under regime I (twin flame spread), as the voltage increases, the FSR of the flame leaning toward the burnt wire decreases and, as the two flames interact, the FSR increases via the ionic wind effect. The FSR then decreases because of the loss of molten PE mass due to the electrospray and di-electrophoresis phenomena. Under regime II (single flame spread), we observed a transient behavior and further research is required. When the voltage was increased further, the flames were extinguished as a result of streamer generation and an electrical short occurred at excessive voltages. The FSR behavior in regime I can best be described according to the functional dependence on $\left|V_{\mathrm{DC}}\right|^{0.91} / S^{0.72}$, which represents the electric field intensity at the outer surface of wire. The results suggest that the fire-safety code developed without considering an applied electric field may need to be modified to consider the situation involving interacting electrical wire fires subject to electric fields.

Note that most of the descriptions here are phenomenological and qualitative in explaining flame spread rate with voltage. Considering the complexity of the phenomena involved, including the phase changes of PE (solid, liquid, and vapor), ionic wind effect, electrospray, and di-electrophoresis, the wire flame spread with electric field is yet to be a challenging problem in quantification based on fundamental physics, which will be a future study. 


\section{Acknowledgment}

This work was supported by the framework of the Research and Development Program of the Korea Institute of Energy Research (B9-2431). SHC \& MSC were supported by King Abdullah University of Science and Technology grant no. (BAS/1/1384-01-01).

\section{Supplementary materials}

Supplementary material associated with this article can be found, in the online version, at doi:10.1016/j.combustflame.2019.09. 003.

\section{References}

[1] F. Jia, M. Patel, E. Galea, A. Grandison, J. Ewer, CFD fire simulation of the Swissair flight 111 in-flight fire. Part II: fire spread within the simulated area, Aeronaut. J. 110 (2006) 303-314

[2] R. Friedman, Fire safety in spacecraft, Fire Mater. 20 (5) (1996) 235-243.

[3] Y. Takeno, O. Fujita, N. Shigeta, Y. Nakamura, H. Ito, Ignition limits of short-term overloaded electric wires in microgravity, Proc. Combust. Inst. 34 (2013) 2665-2673.

[4] X. Huang, Y. Nakamura, F. Williams, Ignition-to-spread transition of externally heated electrical wire, Proc. Combust. Inst. 34 (2013) 2505-2512.

[5] K. Shimizu, M. Kikuchi, N. Hashimoto, O. Fujita, A numerical and experimental study of the ignition of insulated electrical wire with long-term excess current supply under microgravity, Proc. Combust. Inst. 36 (2017) 3063-3071.

[6] A.F. Osorio, K. Mizutani, C. Fernandez-Pello, O. Fujita, Microgravity flammability limits of ETFE insulated wires exposed to external radiation, Proc. Combust. Inst. 35 (2015) 2683-2689.

[7] M. Kikuchi, O. Fujita, K. Ito, A. Sato, T. Sakuraya, Experimental study on flame spread over wire insulation in microgravity, Symp. (Int.) Combust. 27 (1998) 2507-2514

[8] O. Fujita, K. Nishizawa, K. Ito, Effect of low external flow on flame spread over polyethylene-insulated wire in microgravity, Proc. Combust. Inst. 29 (2002) 2545-2552.

[9] A. Umemura, M. Uchida, T. Hirata, J. Sato, Physical model analysis of flame spreading along an electrical wire in microgravity, Proc. Combust. Inst. 29 (2002) 2535-2543.

[10] Y. Nakamura, N. Yoshimura, K. Ito, K. Azumaya, O. Fujita, Flame spread over electric wire in sub-atmospheric pressure, Proc. Combust. Inst. 32 (2009) 2559-2566.

[11] S. Takahashi, H. Takeuchi, H. Ito, Y. Nakamura, O. Fujita, Study on unsteady molten insulation volume change during flame spreading over wire insulation in microgravity, Proc. Combust. Inst. 34 (2013) 2657-2664.

[12] L. Hu, Y. Zhang, K. Yoshioka, H. Izumo, O. Fujita, Flame spread over electric wire with high thermal conductivity metal core at different inclinations, Proc. Combust. Inst. 35 (2015) 2607-2614.

[13] L. Hu, Y. Lu, K. Yoshioka, Y. Zhang, C. Fernandez-Pello, S.H. Chung, O. Fujita, Limiting oxygen concentration for extinction of upward spreading flames over inclined thin polyethylene-insulated $\mathrm{NiCr}$ wires with opposed-flow under normal- and micro-gravity, Proc. Combust. Inst. 36 (2017) 3045-3053.

[14] R. Friedman, Fire safety in extraterrestrial environments, NASA TM-1998207417, 1998.

[15] R. Friedman, Fire safety in the low-gravity spacecraft environment, NASA TM1999-209285, 1999.

[16] A.G. Ruff, L.D. Urban, K.M. King, A research plan for fire prevention, detection, and suppression in crewed exploration systems, AIAA 2005-0341, 2005.

[17] A.G. Ruff, L.D. Urban, Technology development for fire safety in exploration spacecraft and habitats, AIAA 2007-350, 2007.

[18] NASA STD 6001B, Flammability, offgassing, and compatibility requirements and test procedures, 2011

[19] J.M. Citerne, H. Dutilleul, K. Kizawa, M. Nagachi, O. Fujita, M. Kikuchi, G. Jomaas, S. Rouvreau, J.L. Torero, G. Legros, Fire safety- investigating flame spread interaction over wires, Acta Astronaut. 126 (2016) 500-509.

[20] J. Lawton, F.J. Weinberg, Electrical aspect of combustion, Clarendon Press, Oxford, 1969.

[21] M.K. Kim, S.H. Chung, O. Fujita, Effect of AC electric fields on flame spread over electrical wire, Proc. Combust. Inst. 33 (2011) 1145-1151.
[22] S.J. Lim, M.K. Kim, J. Park, O. Fujita, S.H. Chung, Flame spread over electrical wire with AC electric fields: internal circulation, fuel vapor-jet, spread rate acceleration, and molten insulator dripping, Combust. Flame 162 (4) (2015) $1167-1175$.

[23] S.J. Lim, S.H. Park, J. Park, O. Fujita, S.I. Keel, S.H. Chung, Flame spread over inclined electrical wires with AC electric fields, Combust. Flame 185 (2017) $82-92$.

[24] S.H. Park, S.J. Lim, J. Park, S.H. Chung, Effect of the thickness of polyethylene insulation on flame spread over electrical wire with applied electric field: dielectrophoresis phenomenon, Combust. Flame 202 (2019) 107-118.

[25] R. Lanoie, H.P. Mercure, Influence of forest fire on power line insulation, 6th International Symposium on High Voltage Engineering (1989) Paper 30.06.

[26] W.L. Voslos, J.P. Hozhausen, A.C. Britten, Research into the detection of fires under high voltage lines, 7th International Symposium on High Voltage Engineering (1991) Paper 41.12.

[27] M. Goller, K. Rogalla, HV design of vacuum-insulated power supplies for space applications, IEEE Trans. Electr. Insul. 28 (4) (1993) 667-680.

[28] D.G. Park, S.H. Chung, M.S. Cha, Visualization of ionic wind in laminar jet flames, Combust. Flame 184 (2017) 246-248.

[29] M. Belhi, B.J. Lee, M.S. Cha, H.G. Im, Three-dimensional simulation of ionic wind in a laminar premixed Bunsen flame subject to a transverse DC electric field, Combust. Flame 202 (2019) 90-106.

[30] J.-.M. Citerne, H. Dutilleull, K. Kizawa, M. Nagachi, O. Fujita, M. Kikuchi, G. Jomaas, S. Rouvreau, J. Torero, G. Legros, Fire safety in space - investigating flame spread interaction over wires, Acta Astronaut. 126 (2016) 500-509.

[31] L. Hu, K. Yoshioka, Y. Lu, Y. Zhang, C. Fernandez-Pello, S.H. Chung, O. Fujita, Limiting oxygene concentration (LOC) for extinction of upward spreading flames over inclined electric wires with opposed-flow under normal- and micrigravity, Proc. Combust. Inst. 36 (2017) 3045-3053.

[32] Y. Lu, X. Huang, L. Hu, C. Fernandez-Pello, The interaction between fuel inclination and horizontal wind: experimental study using thin wire, Proc. Combust. Inst. 37 (2019) 3809-3816.

[33] H.A. Pohl, Motion and precipitation of suspensoids in divergent electric fields, J. Appl. Phys. 22 (7) (1951) 869-871.

[34] T.B. Jones, M.P. Perry, J.R. Melcher, Electrostatics and the lab on a chip, Science 174 (1971) 1232-1233.

[35] K.V.I.S. Kaler, R. Prakash, D. Chugh, Droplet microfluidics for chip-based diagnostics, Biomicrofluidics 4 (2010) 1-17 022805.

[36] T.B. Jones, Liquid dielectrophoresis on the microscale, J. Electrostat. 51-52 (2001) 290-299.

[37] T.B. Jones, M. Gunji, M. Washizu, M.J. Feldman, Dielectrophoretic liquid actuation and nanodroplet formation. J. Appl. Phys. 89 (2001) 1441-1448.

[38] R. Ahmed, T.B. Jones, Dispensing picoliter droplets on substrates using dielectrophoresis, J. Electrostat. 64 (2006) 543-549.

[39] P.R.C. Gascoyne, Y. Huang, R. Pethig, J. Vykoukal, F. Becker, Dielectrophoretic segregation of different human cell types on microscope slides, Meas. Sci. Technol. 3 (1992) 439-445.

[40] T.P. Hunt, D. Issadore, R.M. Westervelt, Integrated circuit/microfluidic chip to programmably trap and move cells and droplets with dielectrophoresis, Lab Chip 8 (1) (2007) 81-87.

[41] C.H. Kua, Y.C. Lam, L. Rodriguez, C. Yang, K. Youcef-Toumi, Dynamic cell fractionation and transportation using moving dielectrophoresis, Anal. Chem. 79 (2007) 6975-6987.

[42] H. Moncada-Hernandez, J.L. Baylon-Cardiel, V.H. Perez-Gonzalez, B.H. Lapizco-Encinas, Insulator-based dielectrophoresis of microorganisms: theoretical and experimental results, Electrophoresis 32 (2011) 2502-2511.

[43] L.M. Broche, N. Bhadal, M.P. Lewis, S. Porter, M.P. Hughes, F.H. Labeed, Early detection of oral cancer-Is dielectrophoresis the answer? Oral Oncol. 43 (2007) 199-203.

[44] L. Rayleigh, On the equilibrium of liquid conducting masses charged with electricity, Philos. Mag. 14 (87) (1882) 184-186.

[45] A. Gomez, K. Tang, Charge and fission of droplets in electrostatic sprays, Phys. Fluids 6 (1) (1994) 404-414.

[46] G. Taylor, Disintegration of water droplets in an electric field, Proc. R. Soc. Lond. A: Math. Phys. Eng. Sci. 291 (1965) 145-158.

[47] S.P. Lin, G. Roberts, Waves in a viscous liquid curtain, J. Fluid Mech. 112 (1981) 443-458.

[48] Finite Element Method Magnetics v-4.2. 2018. http://www.femm.info/wiki/.

[49] S.H. Won, S.K. Ryu, M.K. Kim, M.S. Cha, S.H. Chung, Effect of electric fields on the propagation speed of tribrachial flames in coflow jets, Combust. Flame 152 (2008) 496-506. 